\title{
An 80-Carbon Aromatic Saddle Enabled by a Naphthalene-Directed Scholl Reaction
}

\author{
Sai Ho Pun ${ }^{a}$ \\ Chi Kit Chan ${ }^{a}$ \\ Zhifeng Liu ${ }^{a}$ (D) \\ Qian Miao*a (iD) \\ a Department of Chemistry, The Chinese University of Hong Kong, Shatin, \\ New Territories, Hong Kong, China \\ miaoqian@cuhk.edu.hk
}

Received: 16.07.2020

Accepted after revision: 28.07 .2020

DOI: 10.1055/s-0040-1716499; Art ID: om-20-0024sc

License terms: (c)

(C) 2020. The Author(s). This is an open access article published by Thieme under the terms of the Creative Commons Attribution License, permitting unrestricted use, distribution, and reproduction so long as the original work is properly cited. (https:// creativecommons.org/licenses/by/4.0/).

Abstract Synthesis of an unprecedented aromatic saddle consisting of $80 \mathrm{sp}^{2}$ carbons is enabled by including naphthylene groups in the substrate of the Scholl reaction. The negatively curved polycyclic framework of this aromatic saddle is revealed by the single crystal X-ray crystallography, and its stereodynamics are studied with density functional theory calculations.

Key words polycyclic aromatics, eight-membered ring, scholl reaction, negative curvature

\section{Introduction}

The Scholl reaction ${ }^{1}$ is a powerful method for the synthesis of polycyclic aromatics enabling formation of multiple carbon-carbon bonds in a single step. The Scholl reaction proceeding through the radical cation mechanism ${ }^{2}$ is very sensitive to the distribution of the electron density within the substrate, and the oxidative aromatic coupling occurs at the position with the highest electron density. ${ }^{3}$ On the basis of this concept, we have recently demonstrated that the Scholl reactions can be facilitated by introducing naphthalene moieties in the substrate leading to highly curved polycyclic aromatics. ${ }^{4,5}$ Herein, we expand the scope of this strategy by showing successful synthesis of an unprecedented aromatic saddle ( 1 in Scheme 1), which is enabled by including naphthylene groups in the substrate of the Scholl reaction. Aromatic saddles, also known as negatively curved polycyclic arenes, have recently received increasing attention ${ }^{6,7}$ for two reasons. First, they represent fragments in carbon schwarzites ${ }^{8}$
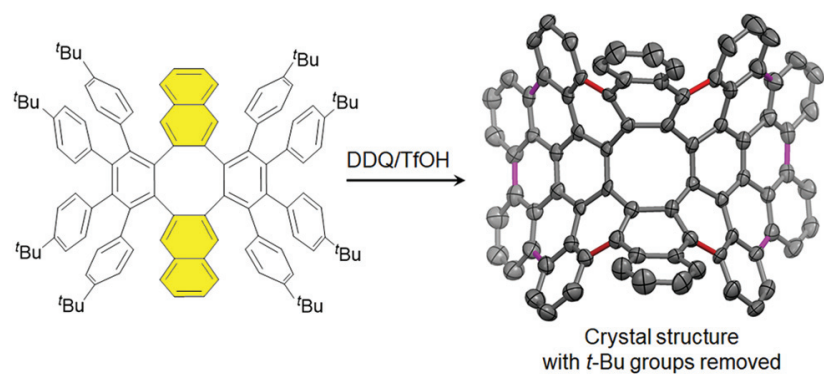

(also known as Mackay crystals ${ }^{9}$ ), which are theoretical negatively curved carbon allotropes of aesthetic structures and interesting properties but have not been synthesized unambiguously yet. ${ }^{10,11}$ Second, they present unique stereochemistry and properties that are not available to planar or positively curved polycyclic arenes.,12 The negative curvature of aromatic saddles is usually induced by embedding seven- or eight-membered rings in a graphitic framework. Compound $\mathbf{1}$ consisting of $80 \mathrm{sp}^{2}$ carbons is a new member of the family of octagon-embedded aromatic saddles, ${ }^{5,13-17}$ which are still less studied than heptagon-embedded aromatic saddles. ${ }^{18}$

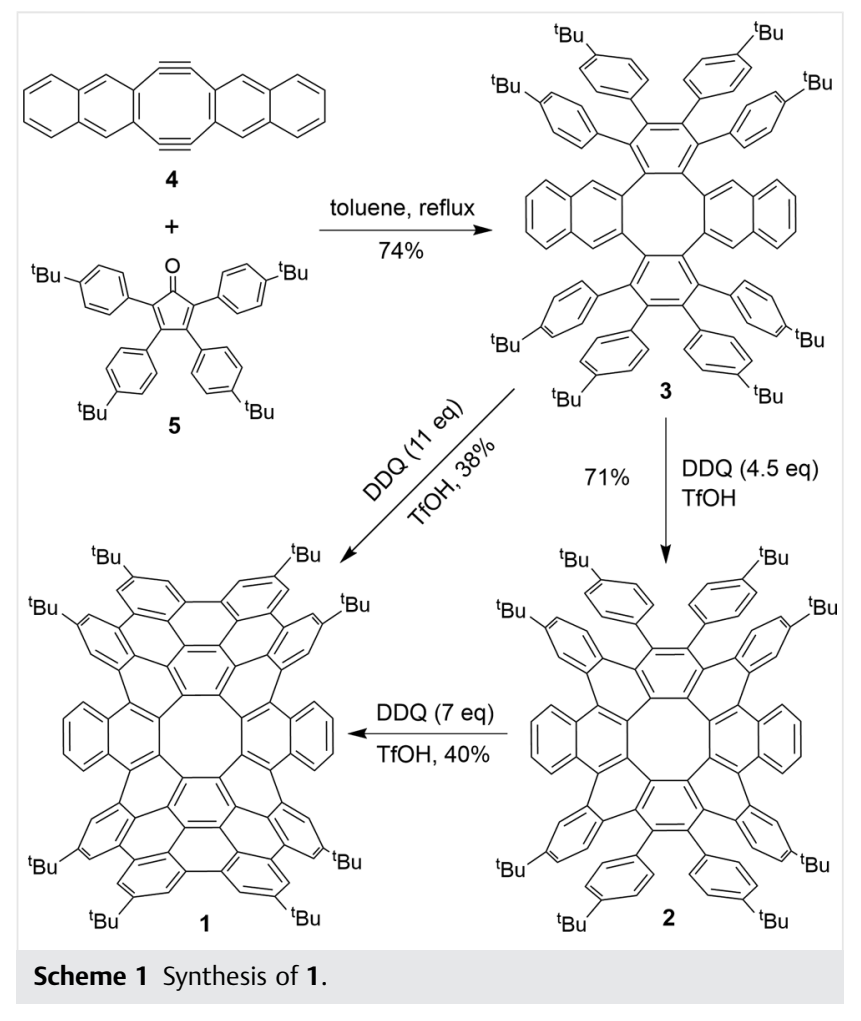


Detailed below are the synthesis, structural analysis, stereochemistry, and electronic properties of $\mathbf{1}$.

\section{Results and Discussion}

Scheme 1 shows the synthesis of $\mathbf{1}$, which started with the twofold Diels-Alder reaction of diyne $\mathbf{4}^{19}$ and cyclopentadienone $\mathbf{5}$ to afford compound $\mathbf{3}$ in a yield of $76 \%$. The Scholl reaction of 3 under strongly acidic conditions $\left(\mathrm{CF}_{3} \mathrm{SO}_{3} \mathrm{H}\right)$ with 11 equivalents of DDQ as an oxidant ${ }^{20}$ at $0{ }^{\circ} \mathrm{C}$ for 6 hours resulted in 1 with the formation of 10 carbon-carbon bonds. In contrast, the reaction of $\mathbf{3}$ with 4.5 equivalents of DDQ under the same conditions for 1 hour resulted in compound $\mathbf{2}$ as the major product (71\%). Compound $\mathbf{2}$ was further converted to $\mathbf{1}$ by subsequent Scholl reaction in a yield of $40 \%$. The two-step yield of 1 (28\%) is comparable to the direct yield (38\%). These results suggest that the formation of $\mathbf{1}$ is through $\mathbf{2}$ with the [8] circulene moiety formed first. When $\mathrm{FeCl}_{3}$ was used as both the oxidant and the Lewis acid in the Scholl reaction of $\mathbf{3}$, compounds $\mathbf{2}$ and $\mathbf{1}$ were also formed in the same subsequent manner, however, accompanied by inseparable chlorinated products as found by MALDI-TOF mass spectroscopy.

In contrast to the above synthesis of $\mathbf{1}$, the Scholl reaction of 6a (Scheme 2) was reported by Müllen and coworkers earlier to result in a partially cyclized product (7a), which was detected only by mass spectroscopy due to its poor solubility. ${ }^{21}$ Elevating the reaction temperature did not enable complete cyclization but gave a rearranged product (8), which was also detected by mass spectroscopy only (Scheme 2). ${ }^{21}$ Similar skeletal rearrangements of octagoncontaining polycyclic arenes under the Scholl reaction

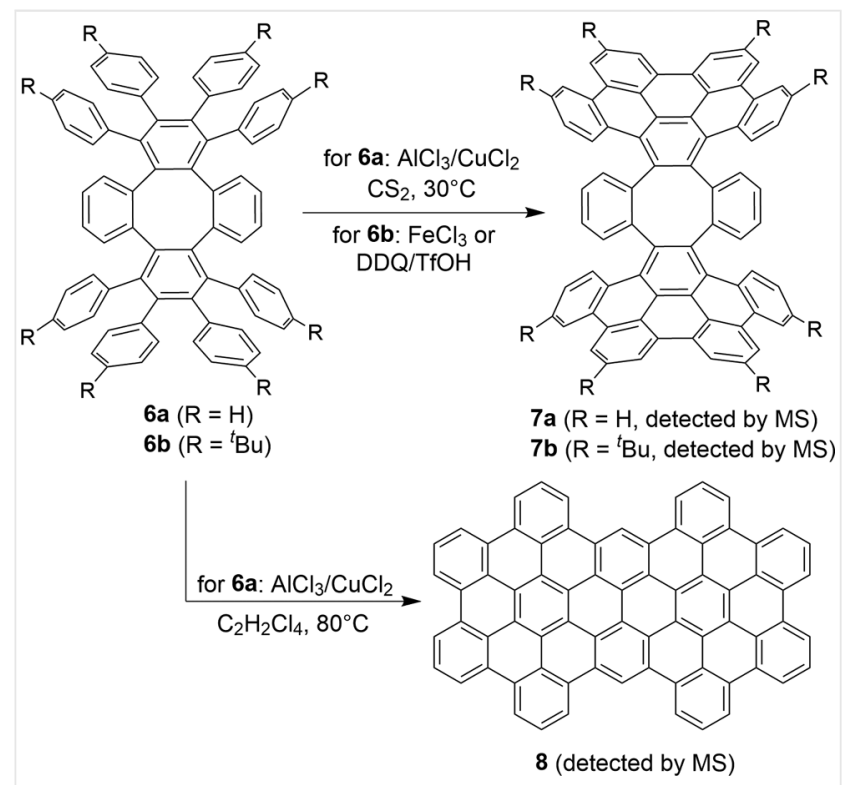

Scheme 2 Cyclodehydrogenation of $\mathbf{6 a / b}$. conditions were also reported by Tobe ${ }^{22}$ and Yamada. ${ }^{23}$ In order to exclude the possibility that the poor solubility of 7a might suppress the further cyclization, we synthesized $\mathbf{6 b}$ with tert-butyl groups to enhance the solubility. The Scholl reaction of $\mathbf{6 b}$ with $\mathrm{FeCl}_{3}$ or $\mathrm{DDQ} / \mathrm{TfOH}$ yielded inseparable mixtures, from which the high-resolution mass spectra indicated formation of a partially cyclized product with a presumable structure of $\mathbf{7 b}$ in good agreement with Müllen's result. The different results of the Scholl reactions of $\mathbf{3}$ and $\mathbf{6 a} / \mathbf{b}$ indicate that the formation of the [8]circulene framework in $\mathbf{1}$ is directed by the naphthalene subunits, which have a higher reactivity at the $\alpha$-positions.

The structure of $\mathbf{1}$ was studied with density functional theory (DFT) calculations and X-ray crystallography. To reduce the computational cost, a simplified model molecule ( $\left.\mathbf{1}^{\prime}\right)$ having eight methyl groups to replace the tert-butyl groups in 1 was calculated at the level of B3LYP/6-31G* of DFT. Geometry optimization reveals that the global energy minimum of $\mathbf{1}^{\prime}$ adopts a saddle-shaped geometry (Saddle-1') with the $C_{2 \mathrm{v}}$ symmetry, while the transition state for saddle-to-saddle inversion adopts a twisted geometry (TS-Twisted-1') with the $D_{2}$ symmetry, as shown in Figure 1a. In contrast, the previously reported octagon-embedded twisted nanographene (9 in Figure S2) presents the $D_{2}$ symmetry at the global minimum and the $C_{2 v}$ symmetry at the local minimum (see the Supporting Information). ${ }^{15}$ This suggests that the presence of four [4]helicene moieties in $\mathbf{1}$ helps to stabilize the saddle-shaped conformation. As shown in Figure 1b, the saddle-to-saddle inversion of $\mathbf{1}^{\prime}$ occurs through the transition state, TS-Twisted-1', accompanied by conversion of each (P)-

(a)

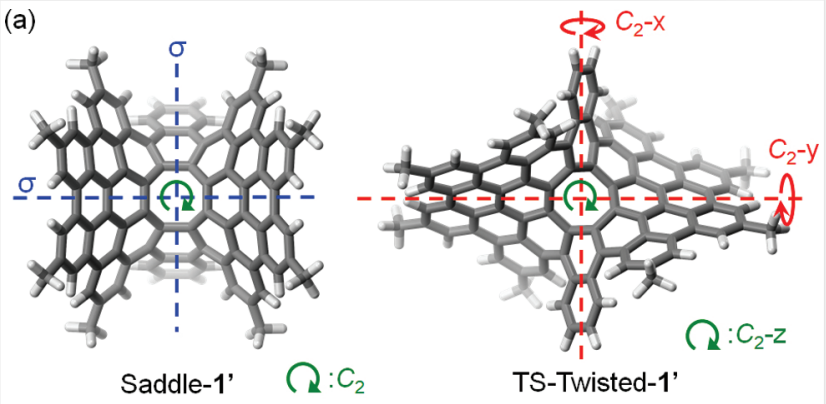

(b)

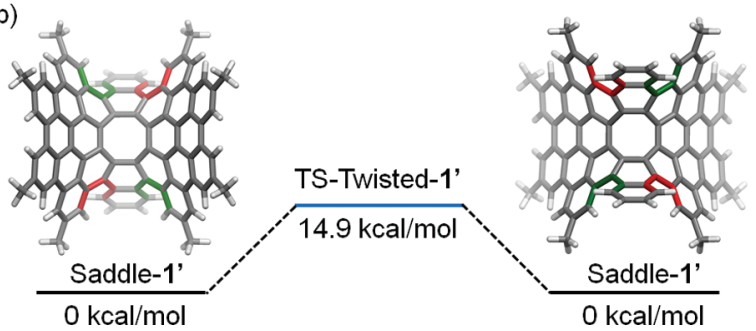

Figure 1 (a) Energy-minimized models for the global minimum (Saddle-1') and the transition state (TS-Twisted-1'); (b) conformational change of $\mathbf{1}^{\prime}$ with relative Gibbs free energy $(\mathrm{kcal} / \mathrm{mol})$ as calculated at the B3LYP/6-31G* level of DFT. 
(a)
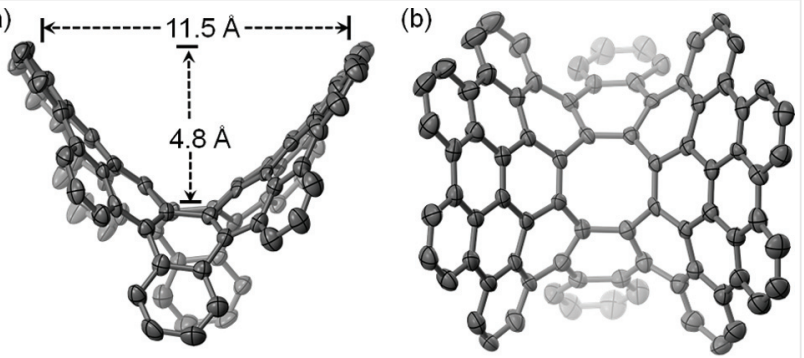

(c)

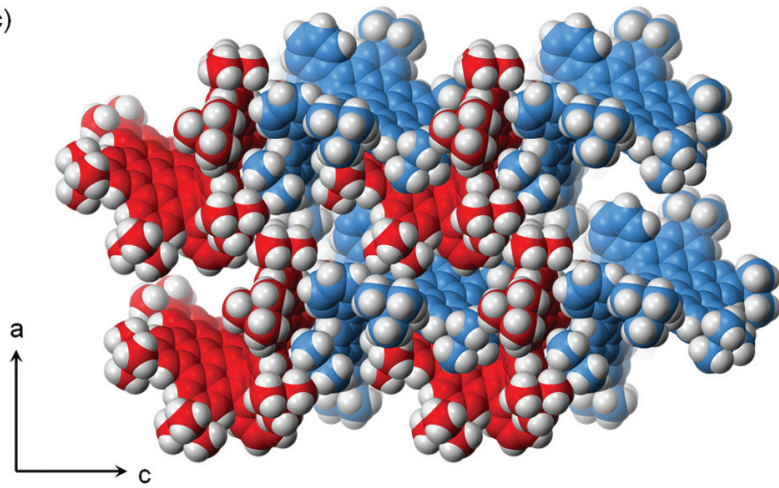

Figure 2 Crystal structure of 1: (a) side view and (b) top view of the polycyclic framework (tert-butyl groups and hydrogen atoms are removed for clarity and carbon atom positions are shown as ellipsoids at $50 \%$ probability level); (c) molecular packing of 1 as viewed along the $b$ axis of the unit cell.

[4]helicene(shown in red) to(M)-[4]helicene (shown in green) and vice versa. The calculated energy barrier for the saddle inversion is $14.9 \mathrm{kcal} / \mathrm{mol}$, which corresponds to a rate constant of $74 \mathrm{~s}^{-1}$ at $25{ }^{\circ} \mathrm{C}$, as estimated using the Eyring equation $k=\mathrm{k}\left(k_{\mathrm{B}} T / h\right) \exp \left(-\Delta G^{\ddagger} / R T\right)$ and assuming a value of unity for the transmission coefficient $(\mathrm{k}){ }^{24}$ The above calculation results indicate that $\mathbf{1}$ has a less flexible polycyclic framework than tetrabenzo[8] circulene $^{13}$ and octabenzo[8] circulene, ${ }^{5}$ which have energy barriers of 7.3 and $9.2 \mathrm{kcal} / \mathrm{mol}$, respectively, for the inversion of saddle. This is presumably a result of fusing [8]circulene with the essentially flat dibenzo $[c d, p q]$ bisanthene moieties, which retard the pseudorotation process of the central [8]circulene moiety in $\mathbf{1}$.

Single crystals of $\mathbf{1}$ suitable for X-ray crystallography were obtained from a solution in mixed $\mathrm{CH}_{2} \mathrm{Cl}_{2}$ and acetonitrile by slow evaporation of solvents. ${ }^{25}$ As shown in Figure 2a, $\mathbf{1}$ is saddle-shaped with a width of $11.5 \AA$ and a depth of $4.8 \AA$. The polycyclic backbone adopts the $C_{2}$ symmetry (Figure 2b), which slightly deviates from the calculated $C_{2 \mathrm{v}}$ symmetry, presumably due to the crystal packing force. As a result of the $C_{2}$ symmetry, 1 is chiral and its crystal lattice consists of a pair of enantiomers, which are shown in red and blue in Figure 2c. The adjacent enantiomers are separated by a $\pi$-to- $\pi$ distance larger than $4.4 \AA$, which is attributable to the peripheral tert-butyl groups blocking the interactions between $\pi$-faces.
Table 1 Analysis of $\mathrm{HOMA}^{\mathrm{a}}$ and nonplanarity ${ }^{\mathrm{b}}$ for individual rings in 1

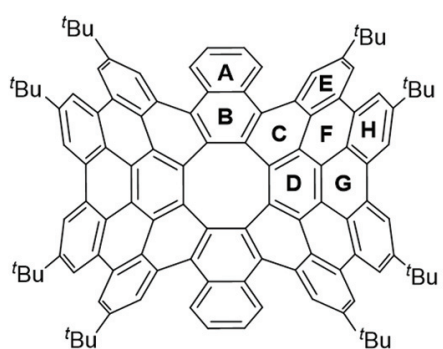

$\begin{array}{ccc}\text { Ring } & \text { Non-planarity } & \text { HOMA } \\ \text { A } & 0.007 & 0.76 \\ \text { B } & 0.166 & 0.31 \\ \text { C } & 0.112 & 0.21 \\ \text { D } & 0.079 & 0.87 \\ \text { E } & 0.011 & 0.95 \\ \text { F } & 0.068 & 0.43 \\ \text { G } & 0.055 & 0.18 \\ \text { H } & 0.017 & 0.85\end{array}$

The HOMA value is calculated by using the normalization constant $(\alpha)$ of 257.7 and the optimal bond length $\left(R_{\text {opt }}\right)$ of $1.388 \AA$.

bThe nonplanarity value is calculated by constructing a best-fit plane for each ring and measuring the average distance of the carbon atoms from this plane.

On the basis of the crystal structures, the local aromaticity of individual rings in $\mathbf{1}$ was analyzed using the harmonic oscillator model of aromaticity (HOMA), ${ }^{26}$ and the curvature of individual rings was analyzed in terms of nonplanarity. ${ }^{27} \mathrm{As}$ shown in Table 1 , rings $A, D, E$, and $H$ present significantly larger HOMAvalues than other rings. This is in agreement with the aromatic sextets predicted by the Clar's rule. ${ }^{28}$ In contrast, rings $B$ and $C$ have the HOMA values as low as 0.21 and 0.31 , respectively, indicating that they are largely nonaromatic. The [8]circulene moiety in $\mathbf{1}$ has only two aromatic sextets (ring D) with a HOMA value of 0.87 . In contrast, the earlier reported peri-substituted [8]circulene has four aromatic sextets with a HOMA value of $0.63 .{ }^{14}$ As shown in Table 1, rings $B$ and $C$ are the most curved hexagons in $\mathbf{1}$ having the nonplanarity values larger than 0.11, in agreement with their small HOMA values. The six-membered ring with lower aromaticity (e.g. a lower HOMA value) has a better chance to be bent in the curved $\pi$ backbone. In comparison to them, the rings in dibenzo[cd,pq] bisanthene units are essentially flat with nonplanarity values in the range of 0.011 to 0.068 , indicating that the curvature is concentrated on the central [8]circulene moiety.

Compound 1 dissolved in $\mathrm{CH}_{2} \mathrm{Cl}_{2}$ forming an orange solution, which exhibited weak yellowish orange luminescence upon irradiation with UV light. Figure 3 shows the UV absorption spectrum of $\mathbf{1}$ with the absorption edge at $578 \mathrm{~nm}$ and the emission spectrum of 1 with peaks at 495, 
Figure 3 UV-vis absorption (black solid line) and fluorescence (blue dashed line, recorded with excitation at $365 \mathrm{~nm}$ ) spectra of $\mathbf{1}$ in solution $\left(1 \times 10^{-5} \mathrm{M}\right)$ in $\mathrm{CH}_{2} \mathrm{Cl}_{2}$.

524 , and $568 \mathrm{~nm}$. The cyclic voltammogram of 1 in $\mathrm{CH}_{2} \mathrm{Cl}_{2}$ in the testing window exhibited two reversible oxidation waves with the half-wave oxidation potential of 0.35 and $0.66 \mathrm{~V}$, respectively, versus ferrocenium/ferrocene (Figure S1 in the Supporting Information). Based on the first oxidation potential, the HOMO energy level is estimated to be $-5.45 \mathrm{eV}^{29}$

\section{Conclusions}

In summary, the successful synthesis of the new octagon-embedded aromatic saddle (1) indicates that the earlier reported problems of incomplete cyclization or skeletal rearrangement during the Scholl reaction can be solved by introducing naphthalene moieties to the substrate. This synthesis, together with other recent successes in the synthesis of strained nonplanar polycyclic aromatics, indicates that, in contrast to earlier assumptions, the Scholl reaction is capable of ring closure accompanied by the introduction of significant steric strain ${ }^{30}$ when the substrates are rationally designed.

\section{Funding Information}

This work was supported by the Research Grants Council of Hong Kong (GRF 14300919) and the Croucher Senior Research Fellowship.

\section{Acknowledgment}

We thank Ms. Hoi Shan Chan (the Chinese University of Hong Kong) for the help with the single-crystal crystallography.

\section{Supporting Information}

Supporting information for this article is available online at https://doi.org/10.1055/s-0040-1716499.

\section{References}

(1) (a) Scholl, R.; Mansfeld, J. Ber. Dtsch. Chem. Ges. 1910, 43, 1734. (b) Scholl, R.; Seer, C.; Weitzenböck, R. Ber. Dtsch. Chem. Ges. 1910, 43, 2202.

(2) Rempala, P.; Kroulík, J.; King, B. T. J. Org. Chem. 2006, 71, 5067.

(3) Grzybowski, M.; Skoniczny, K.; Butenschön, H.; Gryko, D. T. Angew. Chem. Int. Ed. 2013, 52, 9900.

(4) (a) Yang, Y.; Yuan, L.; Shan, B.; Liu, Z.; Miao, Q. Chem. Eur. J 2016, 22, 18620. (b) Cheung, K. Y.; Gui, S.; Deng, C.; Liang, H.; Xia, Z.; Liu, Z.; Chi, L.; Miao, Q. Chem 2019, 5, 838.

(5) Pun, S. H.; Wang, Y.; Chu, M.; Chan, C. K.; Li, Y.; Liu, Z.; Miao, Q.J. Am. Chem. Soc. 2019, 141, 9680.

(6) (a) Narita, A.; Wang, X.-Y.; Feng, X.; Müllen, K. Chem. Soc. Rev. 2015, 44, 6616. (b) Segawa, Y.; Ito, H.; Itami, K. Nat. Rev. Mater. 2016, 1, 15002. (c) Rickhaus, M.; Mayor, M.; Juríček, M. Chem. Soc. Rev. 2017, 46, 1643. (d) Márquez, I. R.; CastroFernández, S.; Millán, A.; Campaña, A. G. Chem. Commun. 2018, 54, 6705. (e) Stępień, M.; Majewski, M. A. Angew. Chem. Int. Ed. 2019, 58, 86.

(7) Pun, S. H.; Miao, Q. Acc. Chem. Res. 2018, 51, 1630.

(8) Terrones, H. Fullerenes and Beyond: Complexity, Morphology, and Functionality in Closed Carbon Nanostructures. In Springer Handbook of Nanomaterials. Vajtai, R. Springer: Berlin, 2013 , 83-104.

(9) Mackay, A. L.; Terrones, H. Nature 1991, 352, 762.

(10) Kim, K.; Lee, T.; Kwon, Y.; Seo, Y.; Song, J.; Park, J. K.; Lee, H.; Park, J. Y.; Ihee, H.; Cho, S. J.; Ryoo, R. Nature 2016, 535, 131.

(11) Braun, E.; Lee, Y.; Moosavi, S. M.; Barthel, S.; Mercado, R.; Baburin, I. A.; Proserpio, D. M.; Smit, B. Proc. Natl. Acad. Sci. U.S.A. 2018, 115, E8116.

(12) Lin, H.-A.; Sato, Y.; Segawa, Y.; Nishihara, T.; Sugimoto, N.; Scott, L. T.; Higashiyama, T.; Itami, K. Angew. Chem. Int. Ed. 2018, 57, 2874.

(13) Sakamoto, Y.; Suzuki, T. J. Am. Chem. Soc. 2013, 135, 14074.

(14) Feng, C.-N.; Kuo, M.-Y.; Wu, Y.-T. Angew. Chem. Int. Ed. 2013, 52, 7791.

(15) Cheung, K. Y.; Chan, C. K.; Liu, Z.; Miao, Q. Angew. Chem. Int. Ed. 2017, 56, 9003.

(16) Miller, R. W.; Duncan, A. K.; Schneebeli, S. T.; Gray, D. L.; Whalley, A. C. Chem. Eur. J 2014, 20, 3705.

(17) Kirschbaum, T.; Rominger, F.; Mastalerz, M. Angew. Chem. Int. Ed. 2020, 59, 270.

(18) (a) Luo, J.; Xu, X.; Mao, R.; Miao, Q. J. Am. Chem. Soc. 2012, 134, 13796. (b) Kawasumi, K.; Zhang, Q.; Segawa, Y.; Scott, L. T.; Itami, K. Nat. Chem. 2013, 5, 739. (c) Cheung, K. Y.; Xu, X.; Miao, Q.J. Am. Chem. Soc. 2015, 137, 3910. (d) Márquez, I. R.; Fuentes, N.; Cruz, C. M.; Puente-Muñoz, V.; Sotorrios, L.; Marcos, M. L.; Choquesillo-Lazarte, D.; Biel, B.; Crovetto, L.; Gómez-Bengoa, E.; González, M. T.; Martin, R.; Cuerva, J. M.; Campaña, A. G. Chem. Sci. 2017, 8, 1068. (e) Fukui, N.; Kim, T.; Kim, D.; Osuka, A. J. Am. Chem. Soc. 2017, 139, 9075. (f) Oki, K.; Takase, M.; Mori, S.; Shiotari, A.; Sugimoto, Y.; Ohara, K.; Okujima, T.; Uno, H. J. Am. Chem. Soc. 2018, 140, 10430. (g) Fernández-García, J. M.; Evans, P. J.; Medina Rivero, S.; Fernández, I.; García-Fresnadillo, D.; Perles, J.; Casado, J.; Martín, N. J. Am. Chem. Soc. 2018, 140, 
17188. (h) Pun, S. H.; Chan, C. K.; Luo, J.; Liu, Z.; Miao, Q. Angew. Chem. Int. Ed. 2018, 57, 1581. (i) Farrell, J. M.; Grande, V.; Schmidt, D.; Würthner, F. Angew. Chem. Int. Ed. 2019, 131, 16656.

(19) Wong, H. N. C.; Man, Y.-M.; Mak, T. C. W. Tetrahedron Lett. 1987, 28, 6359.

(20) Zhai, L.; Shukla, R.; Rathore, R. Org. Lett. 2009, 11, 3474.

(21) Müller, M.; Iyer, V. S.; Kübel, C.; Enkelmann, V.; Müllen, K. Angew. Chem. Int. Ed. 1997, 36, 1607.

(22) Nobusue, S.; Fujita, K.; Tobe, Y. Org. Lett. 2017, 19, 3227.

(23) Tamoto, A.; Aratani, N.; Yamada, H. Chem. Eur. J y 2017, 23, 16388.

(24) Anslyn, E. V.; Dougherty, D. A. Energy Surfaces and Kinetic Analyses. In Modern Physical Organic Chemistry. University Science Books: Sausalito, CA, 2004, 355-419.
(25) CCDC 2020898 contains the supplementary crystallographic data for $\mathbf{1}$. These data can be obtained free of charge from The Cambridge Crystallographic Data Centre.

(26) (a) Kruszewski, J.; Krygowski, T. M. Tetrahedron Lett. 1972, 13, 3839. (b) Krygowski, T. M. J. Chem. Inf. Comput. Sci. 1993, 33, 70. (c) Krygowski, T. M.; Cyrański, M. K. Chem. Rev. 2001, 101, 1385.

(27) The average distance of the carbon atoms in a ring from a generated best-fit plane was used to evaluate the nonplanarity of a ring in polycyclic arenes but was named as planarity. See: Ref. 16 .

(28) Clar, E. The Aromatic Sextet. Wiley: New York, 1972.

(29) Cardona, C. M.; Li, W.; Kaifer, A. E.; Stockdale, D.; Bazan, G. C. Adv. Mater. 2011, 23, 2367.

(30) Grzybowski, M.; Sadowski, B.; Butenschön, H.; Gryko, D. T. Angew. Chem. Int. Ed. 2020, 59, 2998. 